\title{
The Increase in Addiction during COVID-19
}

\author{
Theodoros Daglis (1)
}

check for

updates

Citation: Daglis, $\mathrm{T}$. The Increase in Addiction during COVID-19.

Encyclopedia 2021, 1, 1257-1266.

https://doi.org/10.3390/

encyclopedia1040095

Academic Editor: Stephen Bustin

Received: 19 September 2021

Accepted: 22 November 2021

Published: 24 November 2021

Publisher's Note: MDPI stays neutral with regard to jurisdictional claims in published maps and institutional affiliations.
Postdoctoral Research Fellow, Laboratory of Theoretical \& Applied Economics, School of Applied Mathematics \& Physics, Zografou Campus, National Technical University of Athens,

Heroon Polytechneiou 9, 15780 Athens, Greece; theodagl4@gmail.com

Definition: The increase in addiction during COVID-19 is a condition that emerged as an aftermath of COVID-19-related events, for instance, fear of the spread of COVID-19, self-abstention from many activities, and restrictions established by the lockdown measures. This condition includes substance addictions such as drugs and alcohol but also behavioral addictions such as gambling, gaming, pornography, and smartphone and internet misuse.

Keywords: COVID-19; addiction; oppression

\section{Introduction}

COVID-19 has negatively affected society in many ways. The COVID-19 pandemic has caused in individuals the fear of contagion, leading to self-abstention from many social activities. Additionally, the lockdown measures limited even more citizens' activities, since only some of them were allowed, leading to even more oppression, with a physical and psychological aftermath [1]. In such difficult and prolonged periods, social and emotional closeness with relatives, colleagues, and friends are necessary [2], to adequately confront the difficult period without self-destructive practices.

Isolation can affect negatively individuals, rendering them lonely and abandoned, creating a vicious cycle of withdrawal and isolation [2]. In such cases of continuous and acute oppression, many people try to find alleviation in anti-stress behaviors. The problem is that some anti-stress behaviors are not healthy, since they may have a severe and longterm negative impact on individuals. To be more precise, many people resort to addictive practices, such as excessive gaming, gambling, illegal substances, alcohol consumption, etc. [3], since the aforementioned have a direct and short-run stress relief result, but the long-run consequences of these behaviors have a serious and negative impact on health, perpetuating a negative non-ending situation, which is termed as addiction.

Even though COVID-19 had unprecedented effects on society, many researchers in the past had highlighted the effect of crises on human behavior. There are many pieces of evidence, unveiling that the oppression caused by economic, financial, and other crises and also by unemployment make people more vulnerable to addictive behaviors [4]. In this context, it is very important to understand social phenomena that have a major impact on human societies, concealing also a probable biological or even genetic tendency of humans to addiction. A thorough examination of this specific field of study is imperative.

The present entry provides an extensive literature review for the main findings regarding addiction during COVID-19. Furthermore, the entry describes empirically the academic interest for the subject of "addiction" over the years, points out alternative investigations for this specific field of study, and, finally, concludes with some probable measures that can be taken to face such social phenomena.

\section{The Addiction}

"Addiction" as a term originally referred to substances and, more precisely, to drugs. In the past, the literature focused mainly on three types of substance use: (a) occasional 
controlled and/or social, (b) abuse or harmful use, and (c) addiction [5]. Based on the current literature, addiction is a biopsychosocial negative condition with its main characteristic being the compulsive engagement, in one or multiple rewarding stimuli, for instance, substances [6], or compulsive behaviors that do not include substances [7], leading to dependence from these stimuli, with negative consequences. In this context, addictions are categorized into two main groups, namely, chemical addictions, including the use of substances, and behavioral addictions, including compulsive behaviors that are repeated and persistent [8]. Addictions are often linked with many behavioral disorders [9], mental health problems [10], and psychological issues [11]. The case of addictions without the use of substances may include many compulsive and unhealthy practices, such as gambling, gaming, unhealthy sexual practices (addiction to sex), pornography, dangerous behaviors, cyber addiction or addiction to the internet [9], workaholism (addiction to work), addiction to shopping [7], etc.

Addictions exhibit some common attributes since they are characterized as a chronically relapsing disorder, including a compulsion to seek and take the substance or perform the addictive behavior, loss of control in limiting the intake or the action, and the emergence of negative emotional states, such as anxiety, irritability, or dysphoria when access to substance or addictive behavior is prevented [5,12]. Moreover, most of these problematic conditions stimulate certain parts of the brain, mainly through the "brain reward" system, affecting certain neurons, for instance, the dopamine neurons. To give an example, drugs affect the production, elimination, or release of certain neurotransmitters [13], impacting in this way the human brain and, subsequently, human behavior. In some cases, the motivation of addiction is the alleviation of painful feelings while, in others, the control or expression of feelings [14-16]. In general, there are many negative characteristics with addiction, but the most common is the paradox that the individual turns to a specific drug or addictive behavior to alleviate emotional pain, a condition that is later perpetuated, putting the person into a non-ending situation where they are eventually unable to get rid of this pain [5]. In some cases, cortical areas in the frontal lobe may become dysfunctional due to excessive and long-term addiction, which may change even the personality of the individual [13].

All of the aforementioned show the importance of the study of addiction and the necessity of measures to prevent such practices. We should highlight that not all people demonstrate the same tendency for various addictions. For instance, age is an important factor, since adolescents exhibit different characteristics than older ones [17]. In the same context, gender also plays a role, since, based on their gender, people are more prone to certain substances or addictive behaviors [18].

\section{Addiction during COVID-19}

In periods of extensive oppression, people try to alleviate the experienced pain, often with unhealthy and short-term relief practices. If these periods are prolonged, these practices can evolve into addiction, with long-run negative consequences. This is not a piece of unprecedented evidence. Many studies have already examined and shown that recessions provoke an increase in addictions. To be more precise, binge drinking, sporadic use of cannabis, and also heavy use of hypnotics and sedatives increase during economic recessions [19]. Furthermore, binge alcoholism is also related to unemployment levels [20].

Similarly, many researchers have examined the effect of COVID-19 in the increase in addictions. During the COVID-19 pandemic, an upward trend in substance addiction was evidenced [21]. As a result, the availability of the drug supply increased [22], and the coexistence of social isolation, mental health and economic distress, the disruption of health treatment services due to COVID-19 impacted even more this vulnerable population [23,24]. The aforementioned led to more deaths during the COVID-19 pandemic [25,26].

Moreover, through post-analysis from Twitter, certain topics were found to include interest over the difficulties of coping with alcoholism during the rising of the sales of alcohol and the attention to ongoing health crises (for instance, vaping and opioids), 
affordable telehealth services, the relationship between nicotine and COVID-19, concerns about gambling addiction, and changing patterns in substance misuse as drug availability varied [27].

Similarly, the COVID-19 crisis and the associated lockdown measures increased the risk of drinking alcohol [28]. Furthermore, depression symptoms and pandemic-related financial difficulties were associated with tobacco and cannabis use and also with substance co-use, even in the case of pregnant women [29]. On the other hand, there were disparities across the individuals, for instance, the gender, the smoker's residence (urban or rural areas), or the severity of the smoking history of the individual [30]. There was also a relation between the duration of the pandemic and cannabis consumption [31].

Food addiction also increased, which seems to be a uniquely meaningful phenotype, beyond the effects of body mass index (BMI) to identify the repercussions of the COVID19 pandemic [32]. Many adults showed an increase in sugar in their diet during the COVID-19 era, since greater stress related to the pandemic increased sugar intake, drinking, food addiction symptoms, and drinking frequency [33]. Furthermore, exercise addiction was at significantly lower levels during the period post-lockdown, while eating disorder symptomology scores and leisure-time exercise significantly increased during the postCOVID-19 lockdown period [34].

COVID-19 was found to be correlated also with internet addiction [35], depression, and anxiety, with many implications [3,36], especially psychosocial ones [37]. In this context, problematic internet use and internet gaming disorders increased during the pandemic, since people and mainly young individuals, especially those limited at home, resorted to excessive gaming [38]. Furthermore, individuals infected with COVID-19 were at a higher risk for internet gaming disorder and internet addiction [39]. Moreover, a minor increase in pornography viewing was evidenced, especially during the lockdown measures [40], in addition to an increase in the misuse of social networks [41]. More analytically, problematic social media use increased during COVID-19 [42] and was linked with psychological distress and insomnia [43], and a high prevalence rate of social media addiction (SMA) was evidenced [44].

Similarly, during COVID-19, the neuroticism of individuals affected cellphone addiction through online social anxiety, while extraversion affected cellphone addiction through cyber danger beliefs [45]. There was a negative effect of COVID-19 in the problematic use of smartphones from young persons, with a negative impact on their psychological and physical health [1]. A mediator between COVID-19-related exposure and post-traumatic stress disorder (PTSD) symptoms seems to be problematic smartphone use, and, in the same context, daytime sleepiness was found to partially mediate the associations between problematic smartphone use and PTSD [46]. However, the indirect association between perceived stress and mobile phone addiction can be moderated by self-control [47]. COVID-19 phobia and COVID-19 news exposure are substantial determinants of consumers' smartphone addiction, which in turn affect mobile shopping frequency, and social influence plays an important role in moderating mobile shopping frequency for individuals who seem to experience smartphone addiction [48].

The COVID-19 pandemic has affected online trading [49] and online gambling, which is considered an addictive stress reliever [50], associated with suicide attempts in young men and women, especially when trying to cope with anxiety, life satisfaction, impulsivity, and other factors [51]. For those that showed an increase in gambling behavior, there was frequently an association with problem gambling and not simply gambling behaviors [52].

There are also alternative examinations regarding the addictive behaviors and, more precisely, gambling and excess gaming activities, for instance, through the financial investigation. The rationale is that the COVID-19-related events have made people more prone to addictive behaviors, increasing the revenues of the corresponding companies that are engaged with these activities, causing the investors to turn to these companies' stocks as they are more profitable [53]. These approaches investigated global phenomena, and data were more easily available. 
Many other factors affect individuals differently, playing a significant role in the case of addiction. For instance, there is a difference concerning gender and employment regarding drug consumption [31]. There were found in many individuals symptoms of clinical anxiety and depression, while depression and anxiety symptoms that were associated with the previous trauma exposure, distress and isolation, female gender, alcohol use, and income reduction increased during COVID-19 [54]. Racial-ethnic minorities undergo a greater financial burden and also greater direct adverse effects of COVID-19, including being more concerned about contracting COVID-19, not being able to get a COVID-19 test, and knowing someone who had died from COVID-19 [55]. The cases of a report of child abuse increased during COVID-19, while there is also a differentiation with pre-COVID-19 respective reports since those during COVID-19 seemed to be more emotional or sexual than other types of abuse [56], which are conditions that may lead to addictions as well.

On the other hand, not only has COVID-19 led to an increase in addictions but also many addictions led to an increase in the risk of getting sick with COVID-19. To be more precise, the frequency of risk factors was high for people that are characterized as multi-users, who are also susceptible to worse COVID-19 prognosis [57]. Addicted people are facing many difficulties in accessing healthcare services, rendering them even more vulnerable to drugs by illegal means [26]. A difficulty in the access to the health services that was evidenced, due to treatment disruptions during the COVID-19 pandemic, made matters worse, including reduced access to harm-reduction services, opioid agonist treatment, medical professionals, withdrawal management and treatment services, shelters and housing, and food banks [58]. This decrease in the service capacity resulted in the deterioration of health issues and risky substance-use behaviors among people who use drugs. On the other hand, opioid agonist treatment take-home "carries" cited greater access and also more prescription deliveries [58].

Policymakers shifted to more inclusive approaches of co-production of recommendations. The barriers to adoption and implementation that emerged, as a result of the new regulations, included stigma, lack of integration, and overcriminalization [59]. All of the aforementioned affected negatively substance users, and the available help diminished.

Summing up, COVID-19 is related to many addictions that increased during the pandemic. Most of them include internet addiction, gaming, gambling, various drugs, alcohol, and pornography. We should note that even if this phenomenon is of global origin, not all countries and regions exhibit the same magnitude and characteristics. For instance, countries with severe government budgets also decreased the funds in the various health programs, and, similarly, those that have the highest rate of unemployment are those whose citizens are more prone to adverse consequences of crises [4]. So, not all people were affected in the same way and severity by COVID-19-related events.

As stated above, addictions are mainly categorized into two groups: chemical and behavioral addictions [8]. Based on this distinction, we summarize the literature review findings in Table 1 . We should note that, in the DSM-5, only gambling addiction and internet gaming addiction are categorized as behavioral addictions [60]. However, many researchers include in the behavioral addictions many other problematic behaviors, such as food addiction, pornography addiction, social network addiction, etc. [7], which we also included in our study for completeness reasons. 
Table 1. Literature review summary regarding the addictions during COVID-19.

\begin{tabular}{ccc}
\hline Addiction & Type of Addiction & References \\
\hline Drugs & Chemical & {$[21-29]$} \\
Alcohol & Chemical & {$[21,27-29,33,54]$} \\
Tobacco/vaping & Chemical & {$[21,30]$} \\
Marijuana/cannabis & Chemical & {$[21,31]$} \\
Internet & Behavioral & {$[3,35-37,39]$} \\
Smartphone & Behavioral & {$[1,45-48]$} \\
Gaming & Behavioral & {$[38,39,53]$} \\
Gambling and trading & Behavioral & {$[49-53]$} \\
Food and drinking & Behavioral & {$[32-34]$} \\
Pornography & Behavioral & {$[40]$} \\
Social networks & Behavioral & {$[41-44]$} \\
\hline
\end{tabular}

\section{Scientometric Empirical Evidence}

The scientific interest for specific subjects can be derived and investigated by many methods. A direct method is to examine the research volume produced each year for a specific subject by academia. In this way, we may have an overview of the total academic interest for this specific subject, unveiling the importance of this subject for the research community and society as well. More precisely, by searching the term "addiction" on the ScienceDirect page (https: / /www.sciencedirect.com/ (accessed on 13 September 2021)), and the PubMed page (https://pubmed.ncbi.nlm.nih.gov/ (accessed on 16 November 2021)), we illustrated the academic interest regarding this research field. In Figure 1, we may infer that, in 2018, the scientific works in the ScienceDirect page regarding addiction decreased. On the other hand, in 2019, they increased significantly, and, in 2020, they continued to increase even more. As for the respective scientific works in the PubMed page, there was an upward trend in almost all years, especially the most recent ones, and, more precisely, in 2020, there was an important increase of approximately $15 \%$. The aforementioned evidence shows the importance of this specific field of study, namely, addiction during the COVID-19 pandemic.

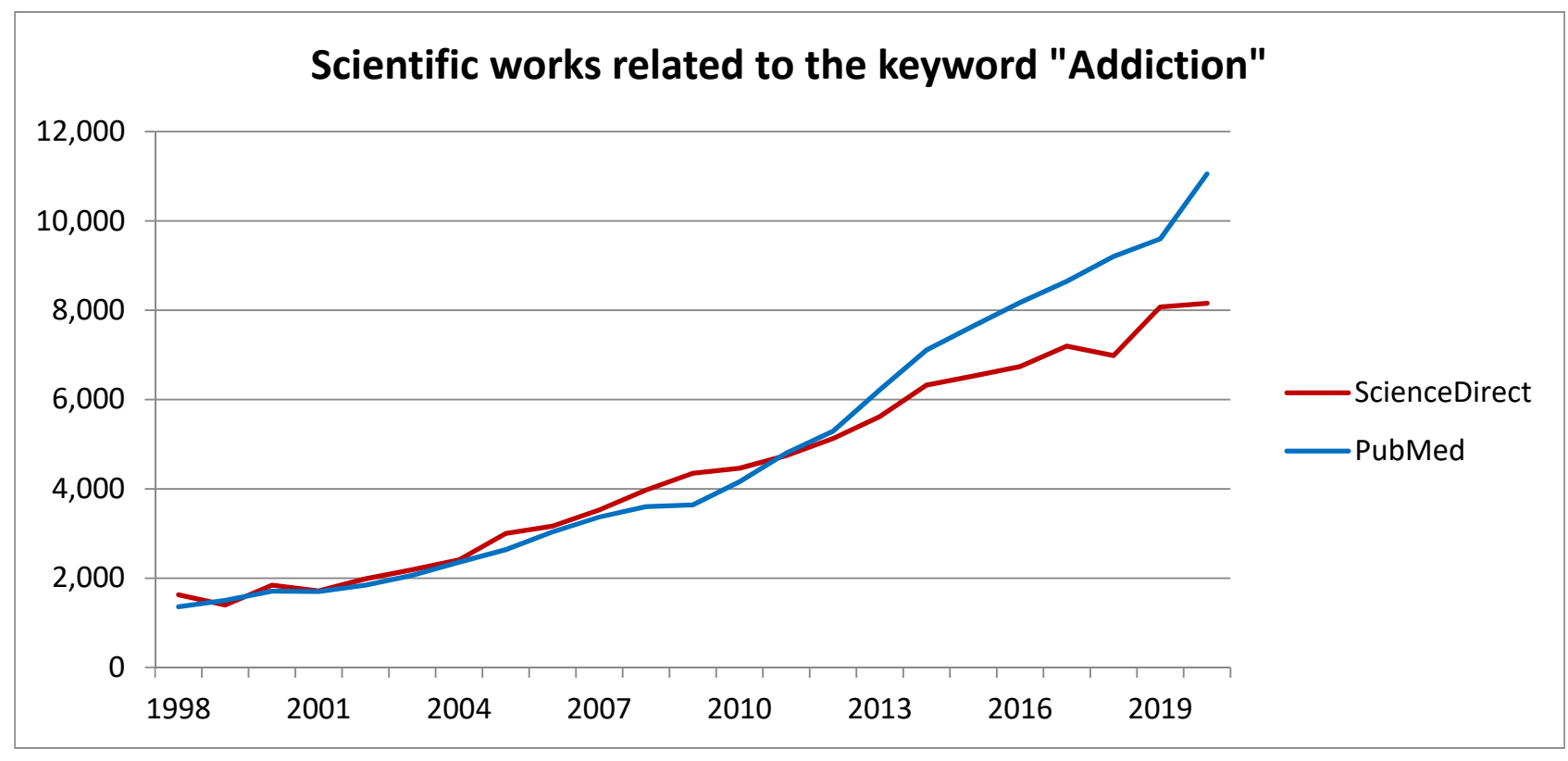

Figure 1. Plot of addiction related research works. 


\section{Conclusions}

The present entry provided an extended literature review for addiction during COVID19 , which is a problematic and important social case that emerged from COVID-19-related events. Based on the literature, during COVID-19, many addictions increased, some of them being substance and alcohol abuse, misuse of the internet, excessive gaming, gambling, pornography, and many others. The present entry contributes to the literature by summarizing and commenting on the literature's findings, highlighting a multifaceted and global problem, which is the increase in multiple addictions during COVID-19, including evidence that most studies do not point out, since most of them are limited in specific addictions, disregarding the overall picture.

In general, in the case of addiction, many factors internal and external can co-exist affecting one another, causing many health and social problems to the individuals. This means that addiction is a multidimensional problem and does not emerge out of nowhere. An important cause for this increase is the oppression caused by the pandemic itself. The fact that during COVID-19, in multiple categories, emergency department psychiatric chief complaint prevalence increased, in comparison with the pre-COVID-19 era [61], shows that the COVID-19 pandemic has impacted significantly human psychology, leading to the search for ways to alleviate this pain, some of which may lead to severe addiction, with an even worse aftermath for the individuals. More precisely, the COVID-19 anxiety and worry, the daily stress, the degradation of the social and health support systems, the anxiety sensitivity of each individual, the probable existence of chronic diseases or psychological problems are all related to certain health and addictive behaviors that also affected the aforementioned [62]. On the other hand, some specific characteristics (e.g., ability to be resilient) can block such problematic cases; for instance, higher sensitivity is not necessarily a vulnerability factor, besides what most would expect, even during the COVID-19 pandemic, if resilience can be enhanced [63]. This evidence shows the importance of interconnection among the various factors that affect individuals.

Furthermore, another cause for the increase in addictions during COVID-19 is the vulnerability of specific individuals to such unhealthy practices. Not all people were affected in the same way and magnitude by COVID-19-related events, since many factors such as gender, income [54], and racial-ethnic minorities [55] are known to play a significant role. Besides the increase in addictive behaviors due to COVID-19, many addictive behaviors also led to an increase in the risk of getting sick with COVID-19 [57], and people with addictions are at higher risk of multimorbidity and mortality during COVID-19 [21]. This fact shows the importance of the protection of these people who may be in jeopardy. Young people seem to be more affected by technological addiction, for instance, misuse of their smartphone [1] and social media [41] and excessive gaming [38]. Moreover, some results concerning the impact of the COVID-19 on addictive behaviors had some heterogeneity; for instance, COVID-19 had a differential impact on opioid overdoses in certain US states [64], implying that further and more thorough research is needed to have a whole picture.

The social [65] and psychological [66] impacts of COVID-19 for the individuals are of great concern and should not be overseen, since COVID-19 has affected in numerous ways the individuals, for instance, their behavior, or even the way home attachment is perceived by individuals [67]. This can be justified by an increase in domestic violence and unhealthy lifestyle behaviors evidenced during the COVID-19 pandemic [68]. All of these led to a further increase in addictions.

Even though the problem is of great magnitude, it is important to have some lessons from the pandemic itself. In cases that physical touch is difficult, for instance, during lockdown measures, telemedicine could be better utilized, since, during the pandemic, health services were provided very effectively [69]. This fact shows that even in cases of emergency, some actions can help so that the impact will be less intense.

Moreover, the government can play an important role. First, increasing the government budgets for health and other social benefits could alleviate the psychological pain from individuals, so that they will not turn to unhealthy practices. Second, the governmen- 
tal and local institutions could construct appropriate places for outdoor activities, such as swimming and running facilities, since these activities have been shown to affect human psychology positively [70], and render them available free of charge so that more people could have access to them. Finally, many associations could promote athletic activities for the social good, highlighting the positive effects on health.

Furthermore, the COVID-19 pandemic showed that more can be done regarding technological progress, so that people can have access to education and other important activities, as well. Many new tools and interactive teaching methods emerged during the COVID-19 era since there was a need for their utilization in education [71]. Such cases were the virtual laboratories (VLs) that were based on the use of virtual reality (VR), making it feasible and also facilitating the teaching and learning process in a wide range of training activities [71]. As for video games, even though there are drawbacks, for instance, a decrease in sleep duration, an increase in obesity, vision problems [72,73], etc., if the game's content promotes good social behaviors, they can contribute to the social good [74]. Moreover, there are also games that, apart from the social contribution, can promote physical health [75]. In the same context, since many games related to addiction and other dangerous behaviors have been constructed [76], trying to help people and especially adolescents acknowledge the importance of their choices and also the probable aftermath of such behaviors, virtual reality could be utilized in these video games, helping them communicate in a better and more realistic way the problematic conditions associated with addiction.

In conclusion, further analytical study is needed, including interpersonal (qualitative) and local-global (quantitative) studies to cross-validate and analyze the many implications that not only exist but that are also interconnected in a complex system. The case of the COVID-19 pandemic affected even more a problem that already existed and did not cause it out of nowhere.

Funding: This research received no external funding.

Institutional Review Board Statement: This research did not involve humans or animals.

Informed Consent Statement: This research did not involve humans or animals.

Conflicts of Interest: The author has no conflict of interest to declare.

Entry Link on the Encyclopedia Platform: https:/ /encyclopedia.pub/18550.

\section{References}

1. Jin, L.; Hao, Z.; Huang, J.; Akram, H.R.; Saeed, M.F.; Ma, H. Depression and anxiety symptoms are associated with problematic smartphone use under the COVID-19 epidemic: The mediation models. Child. Youth Serv. Rev. 2020, 121, 105875. [CrossRef]

2. Ventriglio, A.; Watson, C.; Bhugra, D. Pandemics, panic and prevention: Stages in the life of COVID-19 pandemic. Int. J. Soc. Psychiatry 2020, 66, 733-734. [CrossRef]

3. Király, O.; Potenza, M.N.; Stein, D.J.; King, D.L.; Hodgins, D.C.; Saunders, J.B.; Griffiths, M.D.; Gjoneska, B.; Billieux, J.; Brand, M.; et al. Preventing problematic internet use during the COVID-19 pandemic: Consensus guidance. Compr. Psychiatry 2020, 100, 152180. [CrossRef] [PubMed]

4. Dubanowicz, A.; Lemmens, P. Chapter 8: Impact of the economic recession on addiction-prone behaviors. In The Impact of Addictive Substances and Behaviours on Individual and Societal Well-Being; Anderson, P., Rehm, J., Room, R., Eds.; Oxford University Press: Oxford, UK, 2015.

5. Koob, F.G.; Le Moal, M. Neurobiology of Addiction; Elsevier: Amsterdam, The Netherlands, 2006.

6. American Psychiatric Association. Diagnostic and Statistical Manual of Mental Disorders, 4th ed.; American Psychiatric Press: Washington, DC, USA, 1994.

7. Semaille, P. The new types of addiction. Rev. Med. Brux. 2009, 30, 335-357.

8. Raypole, C.; Legg, T.J. (Medically Reviewed) Types of Addiction and How They're Treated 2020. Available online: https: //www.healthline.com/health/types-of-addiction\#treating-behavioral-addiction (accessed on 21 November 2021).

9. Johnson, F.N. The Multiplicities of Internet Addiction: The Misrecognition of Leisure and Learning; Ashgate: Farnam, UK, 2009.

10. Chou, W.-P.; Lee, K.-H.; Ko, C.-H.; Liu, T.-L.; Hsiao, R.C.; Lin, H.-F.; Yen, C.-F. Relationship between psychological inflexibility and experiential avoidance and internet addiction: Mediating effects of mental health problems. Psychiatry Res. 2017, 257, 40-44. [CrossRef] [PubMed] 
11. Liu, F.; Zhang, Z.; Chen, L. Mediating effect of neuroticism and negative coping style in relation to childhood psychological maltreatment and smartphone addiction among college students in China. Child Abus. Negl. 2020, 106, 104531. [CrossRef] [PubMed]

12. Koob, G.F.; Le Moal, M. Drug Abuse: Hedonic Homeostatic Dysregulation. Science 1997, 278, 52-58. [CrossRef]

13. Stoehr, D.J. The Neurobiology of Addiction; Chelsea House Publishers: Philadelfea, PA, USA, 2006.

14. Khantzian, E.J. The 1994 distinguished lecturer in substance abuse. J. Subst. Abus. Treat. 1995, 12, 157-165. [CrossRef]

15. Khantzian, E.J. The Self-Medication Hypothesis of Substance Use Disorders: A Reconsideration and Recent Applications. Harv. Rev. Psychiatry 1997, 4, 231-244. [CrossRef]

16. Khantzian, E.J.; Wilson, A. Substance abuse, repetition, and the nature of addictive suffering. In Hierarchical Concepts in Psychoanalysis: Theory, Research, and Clinical Practice; Wilson, A., Gedo, J.E., Eds.; Guilford Press: New York, NY, USA, 1993; pp. 263-283.

17. Essau, A.C. Adolescent Addiction: Epidemiology, Assessment and Treatment (Practical Resources for the Mental Health Professional); Elsevier: Amsterdam, The Netherlands, 2008.

18. Charzyńska, E.; Sussman, S.; Atroszko, P.A. Profiles of potential behavioral addictions' severity and their associations with gender, personality, and well-being: A person-centered approach. Addict. Behav. 2021, 119, 106941. [CrossRef]

19. Colell, E.; Sanchez-Niubo, A.; Delclos, G.L.; Benavides, F.G.; Domingo-Salvany, A. Economic crisis and changes in drug use in the Spanish economically active population. Addiction 2015, 110, 1129-1137. [CrossRef]

20. Dávalos, M.E.; Fang, H.; French, M.T. Easing the pain of an economic downturn: Macroeconomic conditions and excessive alcohol consumption. Health Econ. 2011, 21, 1318-1335. [CrossRef]

21. Mallet, J.; Dubertret, C.; Le Strata, Y. Addictions in the COVID-19 era: Current evidence, future perspectives a comprehensive review. Prog. Neuropsychopharmacol. Biol. Psychiatry 2021, 106, 110070. [CrossRef] [PubMed]

22. Linas, B.P.; Savinkina, A.; Barbosa, C.; Mueller, P.P.; Cerdá, M.; Keyes, K.; Chhatwal, J. A clash of epidemics: Impact of the COVID-19 pandemic response on opioid overdose. J. Subst. Abus. Treat. 2020, 120, 108158. [CrossRef]

23. Cisneros, I.; Cunningham, K. COVID-19 interface with drug misuse and substance use disorders. Neuropharmacology 2021, 198, 108766. [CrossRef] [PubMed]

24. Nguyen, T.; Buxton, J.A. Pathways between COVID-19 public health responses and increasing overdose risks: A rapid review and conceptual framework. Int. J. Drug Policy 2021, 93, 103236. [CrossRef] [PubMed]

25. Slavova, S.; Rock, P.; Bush, H.M.; Quesinberry, D.; Walsh, S.L. Signal of increased opioid overdose during COVID-19 from emergency medical services data. Drug Alcohol Depend. 2020, 214, 108176. [CrossRef]

26. Dubey, M.J.; Ghosh, R.; Chatterjee, S.; Biswas, P.; Chatterjee, S.; Dubey, S. COVID-19 and addiction. Diabetes Metab. Syndr. Clin. Res. Rev. 2020, 14, 817-823. [CrossRef]

27. Glowacki, E.M.; Wilcox, G.B.; Glowacki, J.B. Identifying \# addiction concerns on twitter during the COVID-19 pandemic: A text mining analysis. Subst. Abus. 2020, 42, 39-46. [CrossRef]

28. Daly, M.; Robinson, E. High-Risk Drinking in Midlife Before Versus During the COVID-19 Crisis: Longitudinal Evidence From the United Kingdom. Am. J. Prev. Med. 2020, 60, 294-297. [CrossRef]

29. Kar, P.; Tomfohr-Madsen, L.; Giesbrecht, G.; Bagshawe, M.; Lebel, C. Alcohol and substance use in pregnancy during the COVID-19 pandemic. Drug Alcohol Depend. 2021, 225, 108760. [CrossRef]

30. Yang, H.; Ma, J. How the COVID-19 pandemic impacts tobacco addiction: Changes in smoking behavior and associations with well-being. Addict. Behav. 2021, 119, 106917. [CrossRef]

31. Levy, I.; Cohen-Louck, K.; Bonny-Noach, H. Gender, employment, and continuous pandemic as predictors of alcohol and drug consumption during the COVID-19. Drug Alcohol Depend. 2021, 228, 109029. [CrossRef]

32. Schulte, E.M.; Kral, T.V.; Allison, K.C. A cross-sectional examination of reported changes to weight, eating, and activity behaviors during the COVID-19 pandemic among United States adults with food addiction. Appetite 2021, 168, 105740. [CrossRef] [PubMed]

33. Cummings, J.R.; Ackerman, J.M.; Wolfson, J.A.; Gearhardt, A.N. COVID-19 stress and eating and drinking behaviors in the United States during the early stages of the pandemic. Appetite 2021, 162, 105163. [CrossRef] [PubMed]

34. Trott, M.; Johnstone, J.; Pardhan, S.; Barnett, Y.; Smith, L. Changes in body dysmorphic disorder, eating disorder, and exercise addiction symptomology during the COVID-19 pandemic: A longitudinal study of 319 health club users. Psychiatry Res. 2021, 298, 113831. [CrossRef] [PubMed]

35. IIslam, M.S.; Sujan, M.S.H.; Tasnim, R.; Ferdous, M.Z.; Masud, J.H.B.; Kundu, S.; Mosaddek, A.S.M.; Choudhuri, M.S.K.; Kircaburun, K.; Griffiths, M.D. Problematic internet use among young and adult population in Bangladesh: Correlates with lifestyle and online activities during the COVID-19 pandemic. Addict. Behav. Rep. 2020, 12, 100311. [CrossRef] [PubMed]

36. Servidio, R.; Bartolo, M.G.; Palermiti, A.L.; Costabile, A. Fear of COVID-19, depression, anxiety, and their association with Internet addiction disorder in a sample of Italian students. J. Affect. Disord. Rep. 2021, 4, 100097. [CrossRef]

37. Ozturk, F.O.; Ayaz-Alkaya, S. Internet addiction and psychosocial problems among adolescents during the COVID-19 pandemic: A cross-sectional study. Arch. Psychiatr. Nurs. 2021, 35, 595-601. [CrossRef]

38. López-Cabarcos, M.A.; Ribeiro-Soriano, D.; Piñeiro-Chousa, J. All that glitters is not gold. The rise of gaming in the COVID-19 pandemic. J. Innov. Knowl. 2020, 5, 289-296. [CrossRef] 
39. Oka, T.; Hamamura, T.; Miyake, Y.; Kobayashi, N.; Honjo, M.; Kawato, M.; Kubo, T.; Chiba, T. Prevalence and risk factors of internet gaming disorder and problematic internet use before and during the COVID-19 pandemic: A large online survey of Japanese adults. J. Psychiatr. Res. 2021, 142, 218-225. [CrossRef] [PubMed]

40. Sallie, S.N.; Ritou, V.J.E.; Bowden-Jones, H.; Voon, V. Assessing online gaming and pornography consumption patterns during COVID-19 isolation using an online survey: Highlighting distinct avenues of problematic internet behavior. Addict. Behav. 2021, 123, 107044. [CrossRef]

41. Gómez-Galán, J.; Martínez-López, J.; Lázaro-Pérez, C.; Sánchez-Serrano, J.S. Social Networks Consumption and Addiction in College Students during the COVID-19 Pandemic: Educational Approach to Responsible Use. Sustainability 2020, $12,7737$. [CrossRef]

42. Kalpana, V. Impact of social media use (SMU) on mental health during COVID-19 pandemic, Letter to the Editor. Asian J. Psychiatry 2021, 63, 102767.

43. Lin, C.Y.; Broströmb, A.; Griffithsd, M.D.; Pakpour, A.H. Investigating mediated effects of fear of COVID-19 and COVID-19 misunderstanding in the association between problematic social media use, psychological distress, and insomnia. Internet Interv. 2020, 21, 100345. [CrossRef]

44. Luo, T.; Chen, W.; Liao, Y. Social media use in China before and during COVID-19: Preliminary results from an online retrospective survey. J. Psychiatr. Res. 2021, 140, 35-38. [CrossRef] [PubMed]

45. Zhan, Z.; Wei, Q.; Hong, J.-C. Cellphone addiction during the COVID-19 outbreak: How online social anxiety and cyber danger belief mediate the influence of personality. Comput. Hum. Behav. 2021, 121, 106790. [CrossRef]

46. Hu, T.; Wang, Y.; Lin, L.; Tang, W. The mediating role of daytime sleepiness between problematic smartphone use and posttraumatic symptoms in COVID-19 home-refined adolescents. Child. Youth Serv. Rev. 2021, 126, 106012. [CrossRef]

47. Peng, Y.; Zhou, H.; Zhang, B.; Mao, H.; Hu, R.; Jiang, H. Perceived stress and Mobile phone addiction among college students during the 2019 coronavirus disease: The mediating roles of rumination and the moderating role of self-control. Pers. Individ. Differ. 2021, 185, 111222. [CrossRef]

48. Chopdar, K.P.; Paul, J.; Prodanova, J. Mobile shoppers' response to COVID-19 phobia, pessimism and smartphone addiction: Does social influence matter? Technol. Forecast. Soc. Chang. 2022, 174, 121249. [CrossRef]

49. Chiah, M.; Zhong, A. Trading from home: The impact of COVID-19 on trading volume around the world. Financ. Res. Lett. 2020, 37, 101784. [CrossRef]

50. Wardle, H.; Degenhardt, L.; Ceschia, A.; Saxena, S. The Lancet Public Health. Gambling: A neglected public health issue. Lancet Public Health 2021, 6, e2-e3. [CrossRef]

51. Wardle, H.; McManus, S. Suicidality and gambling among young adults in Great Britain: Results from a cross-sectional online survey. Lancet Public Health 2021, 6, e39-e49. [CrossRef]

52. Brodeur, M.; Audette-Chapdelaine, S.; Savard, A.C.; Kairouz, S. Gambling and the COVID-19 pandemic: A scoping review. Prog. Neuropsychopharmacol. Biol. Psychiatry 2021, 111, 110389. [CrossRef]

53. Daglis, T. The excessive gaming and gambling during COVID-19. J. Econ. Stud. 2021. ahead-of-print. [CrossRef]

54. Blithikioti, C.; Nuño, L.; Paniello, B.; Gual, A.; Miquel, L. Impact of COVID-19 lockdown on individuals under treatment for substance use disorders: Risk factors for adverse mental health outcomes. J. Psychiatr. Res. 2021, 139, 47-53. [CrossRef]

55. Mistler, C.B.; Sullivan, M.C.; Copenhaver, M.M.; Meyer, J.P.; Roth, A.M.; Shenoi, S.V.; Edelman, E.J.; Wickersham, J.A.; Shrestha, R. Differential impacts of COVID-19 across racial-ethnic identities in persons with opioid use disorder. J. Subst. Abus. Treat. 2021, 129, 108387. [CrossRef]

56. Alenezi, S.; Alnamnakani, M.; Temsah, M.-H.; Murshid, R.; Alfahad, F.; Alqurashi, H.; Alonazy, H.; Alothman, M.; Aleissa, M.A. Evaluation of the impact of the COVID-19 pandemic on the reporting of maltreatment cases to the National Family Safety Program in Saudi Arabia. Child Abus. Negl. 2021, 122, 105297. [CrossRef]

57. Benzano, D.; Ornell, F.; Schuch, B.J.; Pechansky, F.; Sordi, O.A.; von Diemen, L.; Kessler, P.H.F. Clinical vulnerability for severity and mortality by COVID-19 among users of alcohol and other substances. Psychiatry Res. 2021, 300, 113915. [CrossRef] [PubMed]

58. Russell, C.; Ali, F.; Nafeh, F.; Rehm, J.; Le Blanc, S.; Elton-Marshall, T. Identifying the impacts of the COVID-19 pandemic on service access for people who use drugs (PWUD): A national qualitative study. J. Subst. Abus. Treat. 2021, 129, 108374. [CrossRef]

59. Henry, B.F.; Campbell, A.; Hunt, T.; Johnson, J.K.; Mandavia, A.D.; Chaple, M.; Arout, C.; Wu, E.; Pincus, H.A.; Nunes, E.V.; et al. COVID-19 related substance use services policy changes: Policymaker perspectives on policy development \& implementation. J. Subst. Abus. Treat. 2021. pre-print. [CrossRef]

60. American Psychiatric Association. Diagnostic and Statistical Manual of Mental Disorders (DSM-5); American Psychiatric Publishing: Washington, DC, USA, 2013.

61. Janoczkin, A.; Kiers, S.; Edara, N.; He, P.; Li, Y. Impact of COVID-19 pandemic on emergency psychiatry-Millcreek community hospital, Erie, PA. Compr. Psychiatry 2021, 110, 152255. [CrossRef]

62. Zvolensky, M.J.; Gareya, L.; Rogersa, A.H.; Schmidtd, N.B.; Vujanovica, A.A.; Storche, E.A.; Bucknerf, J.D.; Paulusg, D.J.; Alfanoa, C.; Smitsh, J.A.J.; et al. Psychological, addictive, and health behavior implications of the COVID-19 pandemic. Behav. Res. Ther. 2020, 134, 103715. [CrossRef]

63. Limura, S. Sensory-processing sensitivity and COVID-19 stress in a young population: The mediating role of resilience. Personal. Individ. Differ. 2022, 184, 111183. 
64. Root, E.D.; Slavova, S.; LaRochelle, M.; Feaster, D.J.; Villani, J.; Defiore-Hyrmer, J.; El-Bassel, N.; Ergas, R.; Gelberg, K.; Jackson, R.; et al. The impact of the national stay-at-home order on emergency department visits for suspected opioid overdose during the first wave of the COVID-19 pandemic. Drug Alcohol Depend. 2021, 228, 108977. [CrossRef]

65. Devine-Wright, P.; Pinto di Carvalho, L.; Di Masso, A.; Lewicka, M.; Manzo, L.; Williams, D. "Re-placed"—Reconsidering relationships with place and lessons from a pandemic. J. Environ. Psychol. 2020, 72, 101502. [CrossRef]

66. Meléndez, J.C.; Satorres, E.; Reyes-Olmedo, M.; Delhom, I.; Real, E.; Lora, Y. Emotion recognition changes in a confinement situation due to COVID-19. J. Environ. Psychol. 2020, 72, 101518. [CrossRef]

67. Meagher, R.B.; Cheadle, D.A. Distant from others, but close to home: The relationship between home attachment and mental health during COVID-19. J. Environ. Psychol. 2020, 72, 101516. [CrossRef]

68. Pakenham, K.I.; Landi, G.; Boccolini, G.; Furlani, A.; Grandi, S.; Tossani, E. The moderating roles of psychological flexibility and inflexibility on the mental health impacts of COVID-19 pandemic and lockdown in Italy. J. Context. Behav. Sci. 2020, 17, 109-118. [CrossRef]

69. Barney, A.; Buckelew, S.; Mesheriakova, V.; Raymond-Flesch, M. The COVID-19 Pandemic and Rapid Implementation of Adolescent and Young Adult Telemedicine: Challenges and Opportunities for Innovation. J. Adolesc. Health 2020, 67, 164-171. [CrossRef]

70. Buckley, R.C.; Brough, P.; Westaway, D. Bringing Outdoor Therapies into Mainstream Mental Health. Front. Public Health 2018, 6, 119. [CrossRef]

71. Vergara, D.; Fernández-Arias, P.; Extremera, J.; Dávila, L.P.; Rubio, M.P. Educational trends post COVID-19 in engineering: Virtual laboratories. Mater. Today Proc. 2021. pre-print. [CrossRef]

72. Foti, K.E.; Eaton, D.K.; Lowry, R.; McKnight-Ely, L.R. Sufficient Sleep, Physical Activity, and Sedentary Behaviors. Am. J. Prev. Med. 2011, 41, 596-602. [CrossRef] [PubMed]

73. Straker, L.; Abbott, R.; Collins, R.; Campbell, A. Evidence-based guidelines for wise use of electronic games by children. Ergonomics 2014, 57, 471-489. [CrossRef] [PubMed]

74. Greitemeyer, T.; Mügge, D.O. Video games do affect social outcomes: A meta-analytic review of the effects of violent and prosocial video game play. Pers. Soc. Psychol. Bull. 2014, 40, 578-589. [CrossRef]

75. Williams, W.M.; Ayres, C.G. Can Active Video Games Improve Physical Activity in Adolescents? A Review of RCT. Int. J. Environ. Res. Public Health 2020, 17, 669. [CrossRef]

76. Dörner, R.; Göbel, S.; Effelsberg, W.; Wiemeyer, J. Serious Games_Foundations. Concepts and Practice; Springer: Berlin/Heidelberg, Germany, 2016; pp. 363-365. 